Planetary Systems in the Universe - Observation, Formation and Evolution

Proceedings IAU Symposium No. 202, (C2004 IAU

Alan Penny, Pawel Artymowicz, Anne-Marie Lagrange, 8 Sara Russell, eds.

\title{
Molecular Observations of Comets: Constraints for Planetary System Formation
}

\author{
Jacques Crovisier, Nicolas Biver, Dominique Bockelée-Morvan \\ and Pierre Colom
}

Observatoire de Paris, F-92195 Meudon, France

Didier Despois

Observatoire de Bordeaux, France

D.C. Lis

California Institute of Technology, Pasadena, USA

Heike Rauer

DRL Inst. of Space Sensor Tech. and Planet. Explor., Berlin, Germany

and the team for target-of-opportunity radio observations of comets

\begin{abstract}
We review our knowledge of the composition of cometary volatiles in the light of recent observations of comets C/1996 B2 (Hyakutake) and C/1995 O1 (Hale-Bopp) and examine how this could constrain models of planetary system formation.
\end{abstract}

The recent observations of comets C/1996 B2 (Hyakutake) and C/1995 O1 (Hale-Bopp), especially at radio wavelengths, led to the detection of many new cometary molecules, thus allowing us to complement our inventory of the composition of cometary volatiles (Bockelée-Morvan 1997, Lis et al. 1997, BockeléeMorvan et al. 2000 and references therein). A summary of the volatile abundances observed in these two comets is given in Table 1 . In addition to abundant species $\left(\mathrm{H}_{2} \mathrm{O}, \mathrm{CO}, \mathrm{CO}_{2}, \mathrm{CH}_{3} \mathrm{OH}, \mathrm{H}_{2} \mathrm{CO} \ldots\right)$, this inventory now includes hydrocarbons, nitrogen compounds $\mathrm{NH}_{3}, \mathrm{HCN}, \mathrm{HNC}, \mathrm{HNCO}, \mathrm{HC}_{3} \mathrm{~N}, \mathrm{CH}_{3} \mathrm{CN}$ ), sulphur compounds $\left(\mathrm{H}_{2} \mathrm{~S}, \mathrm{CS}_{2}, \mathrm{SO}, \mathrm{SO}_{2}, \mathrm{OCS} \ldots\right)$, and fairly complex organic molecules found at the trace level, such as formic acid $(\mathrm{HCOOH}), \mathrm{CH}_{3} \mathrm{CHO}$, $\mathrm{NH}_{2} \mathrm{CHO}, \mathrm{HCOOCH}_{3}$. Isotopic ratios, especially $\mathrm{D} / \mathrm{H}$ in water and $\mathrm{HCN}$, were evaluated (Bockelée-Morvan et al. 1998; Meier et al. 1998a, 1998b). Several species were also searched for unsuccessfully, some of them with stringent upper limits: ethanol, ketene $\left(\mathrm{CH}_{2} \mathrm{CO}\right)$, methanimine $\left(\mathrm{CH}_{2} \mathrm{NH}\right), \mathrm{HC}_{5} \mathrm{~N}$, and many others (a summary of these unpublished results is given in Table 2).

These results provide clues to the composition of the primitive Solar Nebula and give important constraints for models of planetary formation. For the most abundant species $\left(\mathrm{H}_{2} \mathrm{O}, \mathrm{CO}, \mathrm{CO}_{2}, \mathrm{CH}_{3} \mathrm{OH}, \mathrm{H}_{2} \mathrm{CO}, \mathrm{CH}_{4}\right.$, OCS, nitriles X-CN), there is a strong analogy between cometary volatiles and interstellar ices (such as those observed in the infrared by ISO towards deeply embedded protostars 
Table 1. Relative production rates of molecules observed in comets C/1996 $\mathrm{B} 2$ (Hyakutake) and C/1995 O1 (Hale-Bopp) at $r_{h} \approx 1 \mathrm{AU}$.

\begin{tabular}{|c|c|c|c|c|c|}
\hline Molecule & a) & b) & $\mathrm{C} / 1996 \mathrm{~B} 2$ & $\mathrm{C} / 1995 \mathrm{O} 1$ & remark \\
\hline $\mathrm{H}_{2} \mathrm{O}$ & IR & $>5$ & 100 & 100 & \\
\hline $\begin{array}{l}\mathrm{CO} \\
\mathrm{CO}_{2}\end{array}$ & $\begin{array}{l}\text { R IR UV } \\
\text { IR }\end{array}$ & $\begin{array}{c}>5 \\
2\end{array}$ & $\begin{array}{c}6-30 \\
-\end{array}$ & $\begin{array}{c}23 \\
20^{d)}\end{array}$ & extended $^{c)}$ \\
\hline $\begin{array}{l}\mathrm{CH}_{4} \\
\mathrm{C}_{2} \mathrm{H}_{2} \\
\mathrm{C}_{2} \mathrm{H}_{6}\end{array}$ & $\begin{array}{l}\text { IR } \\
\text { IR } \\
\text { IR }\end{array}$ & $\begin{array}{l}2 \\
- \\
2\end{array}$ & $\begin{array}{c}0.7 \\
\approx 0.5 \\
0.4\end{array}$ & $\begin{array}{l}0.6 \\
0.1 \\
0.3\end{array}$ & \\
\hline $\begin{array}{l}\mathrm{CH}_{3} \mathrm{OH} \\
\mathrm{H}_{2} \mathrm{CO} \\
\mathrm{HCOOH} \\
\mathrm{CH}_{3} \mathrm{CHO} \\
\mathrm{HCOOCH}_{3}\end{array}$ & $\begin{array}{c}\text { R IR } \\
\text { R IR } \\
\text { R } \\
\text { R } \\
\text { R }\end{array}$ & $\begin{array}{l}>5 \\
>5 \\
- \\
- \\
-\end{array}$ & $\begin{array}{c}2 \\
0.2-1 \\
- \\
- \\
-\end{array}$ & $\begin{array}{c}2.4 \\
1.1 \\
0.08 \\
0.02 \\
0.08\end{array}$ & extended $\left.^{e}\right)$ \\
\hline $\begin{array}{l}\mathrm{NH}_{3} \\
\mathrm{HCN} \\
\mathrm{HNCO} \\
\mathrm{HNC} \\
\mathrm{CH}_{3} \mathrm{CN} \\
\mathrm{HC}_{3} \mathrm{~N} \\
\mathrm{NH}_{2} \mathrm{CHO}\end{array}$ & $\begin{array}{c}\text { R IR } \\
\text { R IR } \\
\text { R } \\
\text { R } \\
\text { R } \\
\text { R } \\
\text { R }\end{array}$ & $\begin{array}{l}1 ? \\
>5 \\
- \\
1 \\
- \\
- \\
-\end{array}$ & $\begin{array}{c}0.5 \\
0.1 \\
0.07 \\
0.01 \\
0.01 \\
- \\
-\end{array}$ & $\begin{array}{c}0.7 \\
0.25 \\
0.10 \\
0.04 \\
0.02 \\
0.02 \\
0.015\end{array}$ & extended \\
\hline $\begin{array}{l}\mathrm{H}_{2} \mathrm{~S} \\
\mathrm{OCS} \\
\mathrm{SO} \\
\mathrm{CS}_{2} \\
\mathrm{SO}_{2} \\
\mathrm{H}_{2} \mathrm{CS} \\
\mathrm{S}_{2}\end{array}$ & $\begin{array}{c}\mathrm{R} \\
\mathrm{R} \mathrm{IR} \\
\mathrm{R} \\
(\mathrm{R})(\mathrm{UV}) \\
\mathrm{R} \\
\mathrm{R} \\
\mathrm{UV}\end{array}$ & $\begin{array}{l}5 \\
- \\
- \\
>5 \\
- \\
- \\
2\end{array}$ & $\begin{array}{c}0.8 \\
0.1 \\
- \\
0.1 \\
- \\
- \\
0.005\end{array}$ & $\begin{array}{c}1.5 \\
0.4 \\
0.3 \\
0.2 \\
0.2 \\
0.02 \\
-\end{array}$ & $\begin{array}{l}\text { extended } \\
\text { extended } \\
\text { from } \mathrm{CS}^{f} \text { ) }\end{array}$ \\
\hline
\end{tabular}

a) technique of observation ( $\mathrm{R}=$ radio $\left.){ }^{b}\right)$ number of detections in other comets;

c) abundance given for nuclear + extended source; ${ }^{d)}$ measured at $r_{h}=2.9 \mathrm{AU}$;

e) abundance given for extended source; $f$ ) $\mathrm{CS}_{2}$ abundance inferred from CS. Detailed references may be found in Bockelée-Morvan et al. 2000.

(Ehrenfreund \& Schutte 2000). This comparison cannot be extended to trace species because of the lack of sensitivity of infrared observations. A quantitative comparison was also made with the abundances observed by radio spectroscopy in hot molecular cores and bipolar flows (Bockelée-Morvan et al. 2000). There is a very good agreement for the $\mathrm{N}$-bearing and $\mathrm{CHO}$-bearing species. There is less agreement for the S-bearing species, an expected result since the abundances of sulphur species in hot cores and bipolar flows may be affected by a rapid gasphase chemistry in the post-evaporation phase. 
Table 2. Upper limits on the relative production rates of undetected molecules in comets (radio observations).

\begin{tabular}{lllll}
\hline Molecule & $\begin{array}{l}\text { line } \\
{[\mathrm{GHz}]}\end{array}$ & limit $^{a)}$ & telescope & comet \\
& & & \\
\hline $\mathrm{H}_{2} \mathrm{O}_{2}$ & 362.156 & $<0.04$ & CSO & Hyakutake \\
$\mathrm{CH}_{3} \mathrm{CCH}$ & 222.167 & $<0.045$ & IRAM PdB & Hale-Bopp \\
$\mathrm{CH}_{2} \mathrm{CO}$ & 220.178 & $<0.032$ & IRAM 30-m & Hale-Bopp \\
$\mathrm{C}_{2} \mathrm{H}_{5} \mathrm{OH}$ & 235.983 & $<0.05$ & IRAM 30-m & Hale-Bopp \\
$\mathrm{CH}_{3} \mathrm{OCH}$ & several & $<0.45$ & IRAM 30-m & Hale-Bopp \\
$\mathrm{CH}_{3} \mathrm{COOH}$ & several & $b)$ & & Hale-Bopp \\
glycine & several & $<0.5$ & IRAM 30-m & Hale-Bopp \\
$\mathrm{HC}_{5} \mathrm{~N}$ & several & $<0.003$ & IRAM 30-m & Hale-Bopp \\
$\mathrm{CH}_{2} \mathrm{NH}$ & 226.548 & $<0.032$ & IRAM 30-m & Hale-Bopp \\
$\mathrm{CH}_{3} \mathrm{SH}$ & radio & $b)$ & & Hale-Bopp \\
$\mathrm{NaOH}_{\mathrm{NaCl}}^{251.226}$ & $<0.0003$ & CSO & Hale-Bopp \\
$\mathrm{NaCl}$ & 260.223 & $<0.0008$ & CSO & Hale-Bopp \\
\hline \hline
\end{tabular}

a) relative to water $\left.=100 .{ }^{b}\right)$ limit not yet evaluated

The correlations between molecular abundances ranging over several orders of magnitude reinforce the similarity between interstellar and cometary ices. There is now strong evidence that cometary ices were formed to a large extent by the same low temperature non-equilibrium processes which produce interstellar ices: grain surface reactions, condensation of products of ion-molecule reactions, UV processing. But is there a direct link between interstellar and cometary ices? In the inner part of the protoplanetary disc, the high temperature led to a complete volatilization (up to atomisation) of the grains and initiated a specific solar nebula thermochemistry. Assessing to which extent nebular chemistry and additional processes, such as accretion shocks and radial mixing in the nebula, have also contributed to cometary ice composition will need further studies, but the similarities with interstellar ices shown by the present data clearly set a limit to their relative importance.

\section{References}

Bockelée-Morvan, D. 1997, in Molecules in Astrophysics: Probes and Processes, van Dishoeck edt., Kluwer, p. 219

Bockelée-Morvan, D., Gautier, D., Lis, D.C., et al. 1998, Icarus, 147, 162

Bockelée-Morvan, D., Lis, D.C., Wink, J.E., et al. 2000, A\&A, 353, 1101

Ehrenfreund, P. \& Schutte, W.A. 2000, in Astrochemistry, IAU Symp. 197, Y.C. Minh \& E.F. van Dishoeck eds, ASP, p. 135

Lis, D.C., Keene, J., Young, T.G., et al. 1997, Icarus, 130, 355

Meier, R., Owen, T.C., Jewitt, D.C.., et al. 1998a, Science, 279, 1707

Meier, R., Owen, T.C., Matthews, H.E., et al. 1998b, Science, 279, 842 